\title{
A Novel Manufacturing Technology for RF MEMS Devices on Ceramic Substrates
}

\author{
V. Schirosi, G. Del Re, L. Ferrari, P. Caliandro, L. Rizzi, and G. Melone \\ Microelectronic Research, OPTEL InP Consortium Microelectronic Research Lab, c/o Cittadella della Ricerca, \\ S.S. $7 \mathrm{Km}$ 7.3, 72100 Brindisi, Italy \\ Correspondence should be addressed to V. Schirosi, v.schirosi@optel.it
}

Received 12 July 2010; Accepted 7 November 2010

Academic Editor: P. Siciliano

Copyright ( $\odot 2010$ V. Schirosi et al. This is an open access article distributed under the Creative Commons Attribution License, which permits unrestricted use, distribution, and reproduction in any medium, provided the original work is properly cited.

Microelectromechanical systems are often used for their enormous capability and good qualities in T/R modules especially for space modular applications. High isolation and very low insertion loss are guaranteed by their intrinsic working principle. This is a very robust, flexible, and low-cost technology, and it provides high reliability, good reproducibility, and complete fulfillment of technical requirements.

\section{Introduction}

The exploitation of MEMS technology for RF applications enables the manufacturing of high-performance and lowcost lumped components like variable capacitors, inductors, and switches. Starting from these elements, the implementation in MEMS technology of complete subnetworks to be integrated within RF and microwave functional blocks (e.g., RF transceivers) leads to a wider reconfigurability and, consequently, operability of the whole system.

So, RF MEMS technology provides advanced solutions to fabricate very interesting devices for switching of radio frequency signals. This technology allows for reducing drastically device dimensions and number of connections, to operate with signal in large bandwidth, from 0 to $50 \mathrm{GHz}$, with consistent performances. MEMS devices, in fact, have been identified as a promising enabling technology thanks to their extremely reduced dimensions, their high isolation in open-circuit state, and low insertion loss in shortcircuit state, the high linearity. Also, monolithic integration of MEMS devices with transmission lines on substrates with high dielectric constant such as ceramic substrates (aluminum oxide, aluminum nitride, LTCC, etc.) allows manufacturing of complex devices (phase shifters, power dividers, tunable filters, couplers, reconfigurable antennas, etc.) for phase and amplitude modulation which are essential components of TX/RX modules $[1,2]$.

\section{RF MEMS Design}

The RF MEMS devices described have been full designed, fabricated, and tested at Microelectronic Research Lab of Optel Consortium.

Design is carried out by electromechanical and electromagnetic simulation of RF MEMS. Electromechanical design consists of an FEM modeling of micromechanic structures. The goal of the design is the optimization of parameters such as switching time, overshoot, and pull-in voltage. FEM simulations provide an actuation time of $10-15 \mu \mathrm{sec}$, an overshoot less than $13 \%$ of the gap and a pull-in voltage of $15 \mathrm{~V}[3-5]$.

Electromagnetic design consists of full-wave simulations that provide $S$ parameter curves of the device $[6,7]$. For a shunt switch, in OFF state, return loss is better than $-25 \mathrm{~dB}$ and insertion loss is about $-0.1 \mathrm{~dB}$, in the range $0-20 \mathrm{GHz}$. In ON state, return loss is about $-0.1 \mathrm{~dB}$ and isolation is better than $-30 \mathrm{~dB}$ in the range $9.5-16 \mathrm{GHz}$ and, in particular, isolation is higher than $-45 \mathrm{~dB}$ at resonance frequency $(14 \mathrm{GHz})$.

RF MEMS devices are designed in Coplanar Waveguide or Microstrip technology, and every device geometry can be 


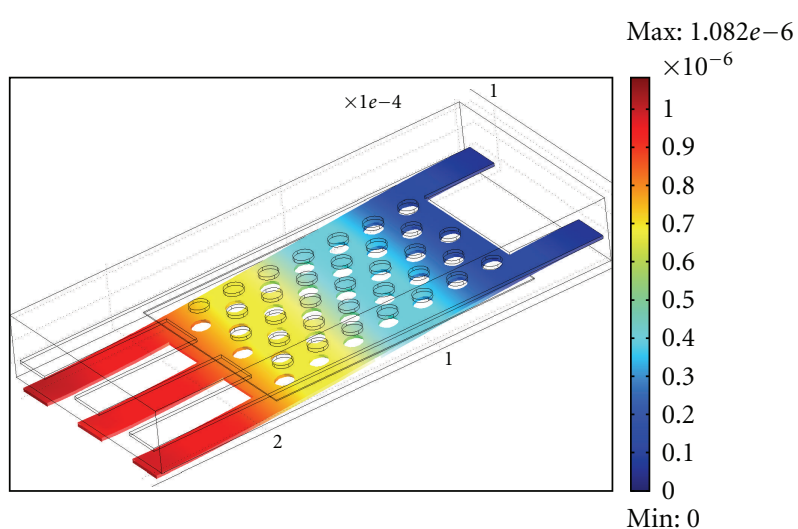

Slice: electric field, norm (V/m) Boundary: total displacement $(\mathrm{m})$ Deformation: displacement

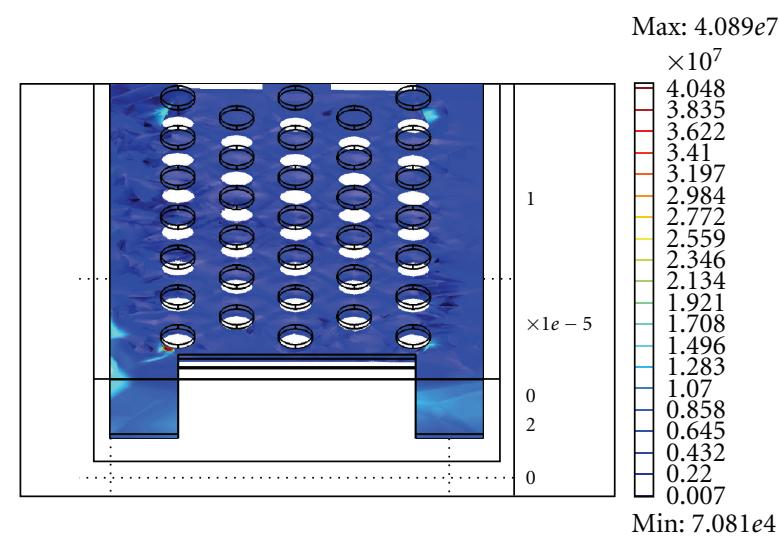

Isosurface: von Mises stress (Pa) Deformation: displacement

(a)

(b)

FiguRE 1: Simulated actuation for a shunt switch membrane (a) and simulated stress concentration on the anchor zone (b).

adapted to any kind of operating bandwidth in the $1: 50 \mathrm{GHz}$ range.

\section{Fabrication on Ceramic Substrate}

RF MEMS fabrication requires only a surface micromachining technology. Optel technology is independent of the substrate used since it requires just thin-film PVD metal deposition, CVD passivation, and gold electroplating.

Optel technology enables the manufacturing of reliable RF MEMS devices onto different substrates:

(i) Si (for consumer electronic and integration with CMOS technology),

(ii) GaAs (for III-V semiconductor technology and subsequent integration in high frequency applications),

(iii) GaN/Si (for monolithic integration with active highpower/high-speed amplifying electronics such as GaN-HEMT).

Also, in addition to semiconductor substrates, RF MEMS devices have been monolithically manufactured on ceramic such as alumina and LTCC polished substrates. Main advantages resulting from the use of ceramic substrates are a good thermal stability, excellent hardness and wear resistance, a good corrosion resistance, excellent dielectric property, and acceptable thermal conductivity. These properties make this substrate suitable for space applications.

RF MEMS devices have been monolithically manufactured on $300 \mu \mathrm{m}$ thick alumina ( 2 inches). The entire process consists of about 100 steps, and it requires 8 photolithographic levels. It is a very robust, flexible, and low-cost technology.

Robustness of the manufacturing process is due to many improvements introduced by Optel technology, both at electrostatic and electromagnetic levels, with respect to MEMS devices on semiconductors. First of all, a ceramic

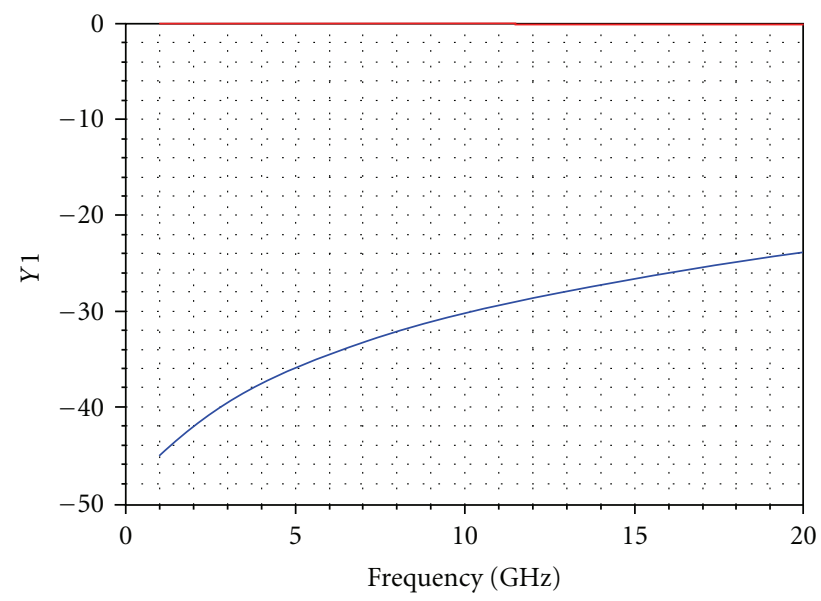

Figure 2: Simulated return loss (blue curve) and insertion loss (red curve) for a shunt switch in OFF state.

substrate, because, its intrinsic high isolation, unlike a semiconductor, does not take part in MEMS operation. Also, a ceramic substrate is not influenced by ionizing radiations, so it avoids many problems of charge generations in space applications. Finally, charge trapping phenomenon, one of the most important causes of failure for RF MEMS on semiconductors, can be completely avoided, just because dielectric is not needed on high-isolation substrate. In fact, removing the dielectric underneath the beam, as well as introducing dimples anchored on the substrate or integrated into the beam to stop the bridge actuation, allows the elimination of the insurgence of charging trapping phenomena and, in addition, allows even the reduction of the pull-in voltage needed for membrane deflection.

Also, Optel technology is low-cost technology, with respect to well-established RF MEMS manufacturing on silicon. In fact, a semiconductor substrate is more expensive than a ceramic substrate, and the technology proposed is a 


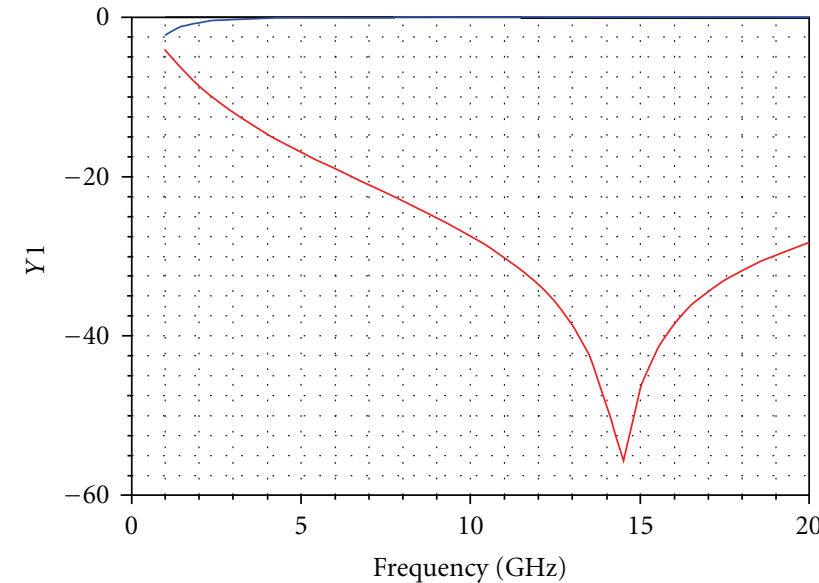

Figure 3: Simulated return loss (blue curve) and isolation (red curve) for a shunt switch in ON state.

process for microelectronic passive devices. This is allowed to done without the process of active IC such as doping, ionic implantation, and oxide growth.

In the standard proposed process for RF MEMS devices, there are 4 metallization layers: a resistive, a conductive, and 2 galvanic thickness layers. They are separated by 2 passivation layers where through vias are opened to provide interconnections with underneath layers. The sacrificial layer is a photoresist upon which the membranes are defined by a galvanic growth.

As first step, a $600-\mathrm{nm}$ thick silicon nitride is deposited as an insulating layer and a high-resistance metal is deposited and defined to create actuation pads and bias lines. Next, a new silicon nitride layer is deposited to provide the high isolation needed for the actuation electrodes. Contact DC vias are then defined and etched within the silicon nitride layer. A multimetal underpass is deposited and defined to create RF lines underneath the bridge, and it is covered by a second passivation layer, which provides an insulating layer for RF lines. Then, RF vias are opened within silicon nitride. Next, a gold layer is deposited and defined in order to provide low-resistance electrical contacts. The sacrificial layer needed for definition of a suspended beam is composed of a $3 \mu \mathrm{m}$ thick photoresist. An Au-based multimetal layer is deposited to obtain the electrical continuity layer, previously to galvanic gold electroplating. Then, a $1 \mu \mathrm{m}$ thick gold layer is grown to define the membranes and a $2 \mu \mathrm{m}$ thick gold layer is grown to define RF lines. Finally, sacrificial layer is removed by a plasma etching process (Figures 4 and 5 ).

For a manufacturing process on ceramic substrate, the passivation layers can be reduced only to small areas where an isolation between DC and RF lines is needed and can be completely removed underneath the bridge.

Critical steps are both membrane definition and sacrificial layer removing. In particular, the reduction of ion bombardment on membranes is a well-known problem that could lead to a stressed and deformed membrane after the dry etching process. In fact, sacrificial layer etching requires a highly confined plasma to minimize the damage on metallic

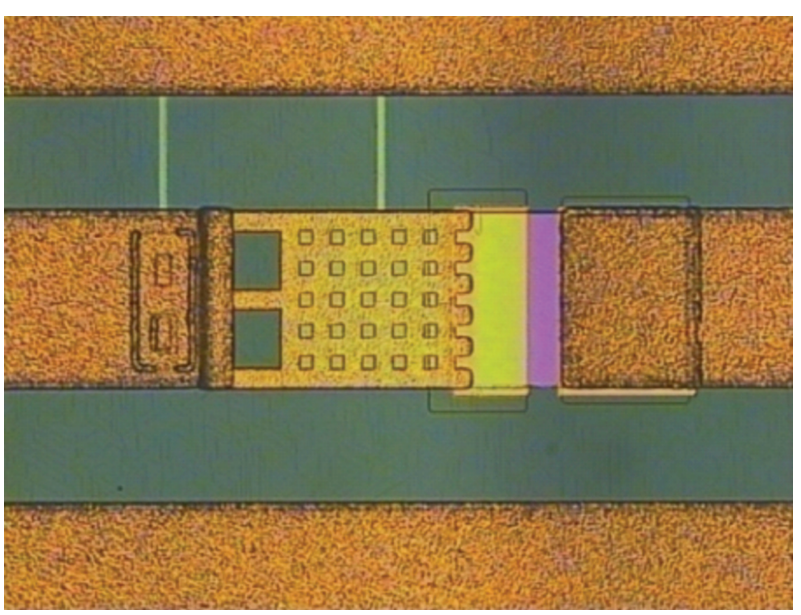

FIgURE 4: Cantilever RF MEMS switch manufactured on alumina substrate.

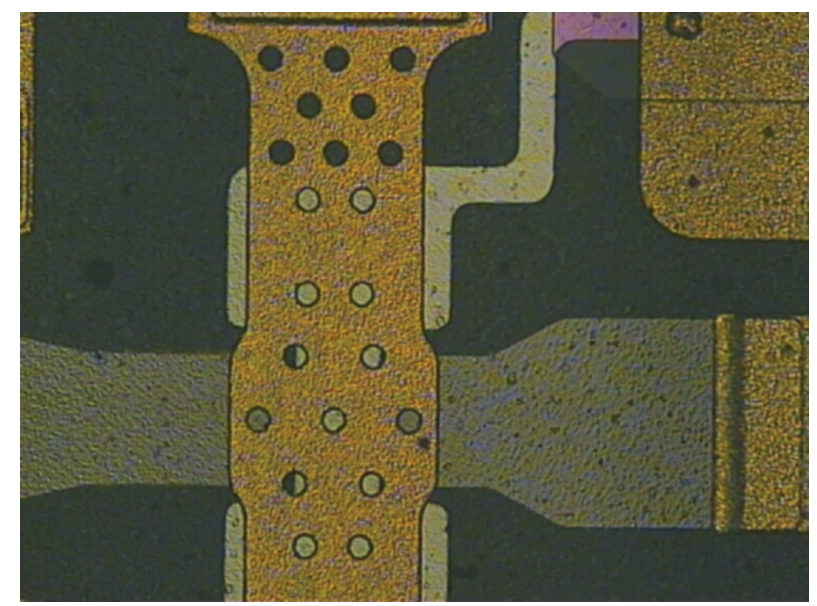

FIgURE 5: Fixed-fixed serie RF MEMS switch manufactured on LTCC substrate.

suspended structures. So, introducing appropriate changes in process conditions, the result has been good. The beams are characterized by very low stress, high flatness, and absence of damage caused by reduced thermal and ion collision during the plasma etching process. Furthermore, mechanic behavior is unchanged both for semiconductors and for bulk or multilayer ceramics (Figure 6).

\section{Measurements}

Testing is carried out on single RF Switch and on RF MEMS microwave circuits. Testing steps include the following:

(i) static DC testing (for measurement of pull-in voltage, contact resistance, and capacitance ratio)

(ii) dynamic DC testing (for measurement of switching times and lifetime testing)

(iii) RF testing (for measurement of return loss, insertion loss, isolation, and phase shift). 
TABLE 1: Performance measured on RF MEMS switches manufactured in Optel, Fondazione Bruno Kessler, and RADANT MEMS.

\begin{tabular}{|c|c|c|c|c|c|}
\hline & \multicolumn{3}{|c|}{ Optel } & \multirow{2}{*}{$\begin{array}{c}\text { University of } \\
\text { Perugia-FBK [8] } \\
\text { Cantilever }\left({ }^{*}\right)\end{array}$} & \multirow{2}{*}{$\begin{array}{l}\text { RADANT MEMS }[9] \\
\text { Cantilever }(*)\end{array}$} \\
\hline & Cantilever & Serie fixed-fixed & Shunt & & \\
\hline Pull-in voltage [V] & 12 & 30 & 45 & 38 & $40-120$ \\
\hline Contact resistance $[\Omega]$ & 6 & 12 & $/ /$ & 1.48 & 1 \\
\hline$C_{\text {ratio }}=C_{\text {down }} / C_{\text {up }}$ & $/ /$ & $/ /$ & 32 & $/ /$ & // \\
\hline Switching time [us] & 6 & 14 & 18 & n.a. & 5 \\
\hline Handled power $[\mathrm{dBm}]$ & -10 & -10 & -10 & 30 & 27 \\
\hline Return loss [dB] & $\begin{array}{c}>25 \mathrm{~dB} \text { up to } \\
20 \mathrm{GHz}\end{array}$ & $>18 \mathrm{~dB}$ up to $20 \mathrm{GHz}$ & $>20 \mathrm{~dB}$ up to $20 \mathrm{GHz}$ & $>30 \mathrm{~dB}$ up to $20 \mathrm{GHz}$ & $>20 \mathrm{~dB}$ up to $36 \mathrm{GHz}$ \\
\hline Insertion loss $[\mathrm{dB}]$ & $\begin{array}{c}<0.8 \mathrm{~dB} \text { up to } 20 \\
\mathrm{GHz}\end{array}$ & $<0.8 \mathrm{~dB}$ up to $20 \mathrm{GHz}$ & $\begin{array}{c}<0.25 \mathrm{~dB} \text { up to } \\
20 \mathrm{GHz}\end{array}$ & $<0.3 \mathrm{~dB}$ up to $20 \mathrm{GHz}$ & $<0.5$ up to $38 \mathrm{GHz}$ \\
\hline Isolation $[\mathrm{dB}]$ & $\begin{array}{l}>25 \mathrm{~dB} \text { up to } \\
20 \mathrm{GHz}\end{array}$ & $>25 \mathrm{~dB}$ up to $20 \mathrm{GHz}$ & $\begin{array}{l}>20 \mathrm{~dB} \text { at } 8-20 \mathrm{GHz} \\
>33 \mathrm{~dB} \text { at resonance }\end{array}$ & $\begin{array}{l}>20 \mathrm{~dB} \text { up to } 13 \mathrm{GHz} \\
>10 \mathrm{~dB} \text { up to } 40 \mathrm{GHz}\end{array}$ & $\begin{array}{l}20 \mathrm{~dB} @ 10 \mathrm{GHz}, \\
13 \mathrm{~dB} @ 40 \mathrm{GHz}\end{array}$ \\
\hline Lifetime $\left[{ }^{\#}\right.$ cycles $\left.>10^{8}\right]$ & no failure & no failure & no failure & no failure & no failure \\
\hline
\end{tabular}

$\left(^{*}\right)$ switches manufactured on High Resistivity Silicon.

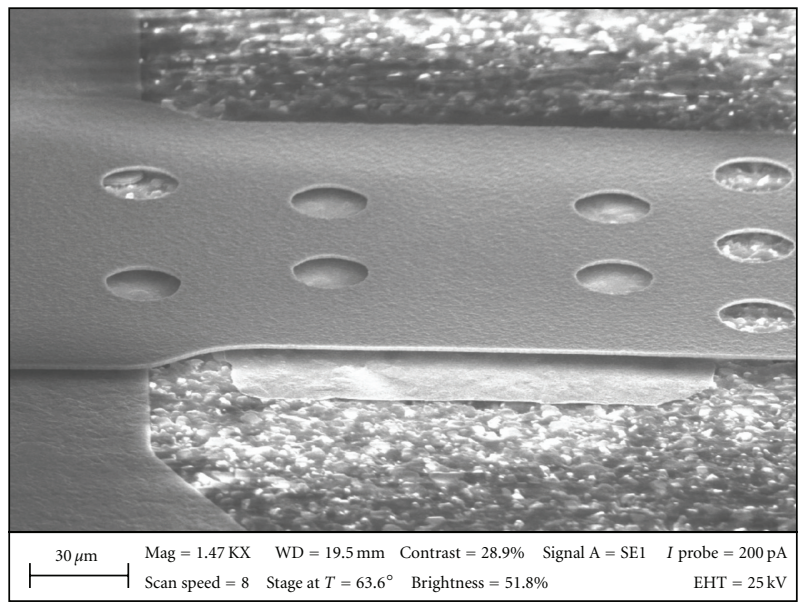

Figure 6: SEM view of a suspended beam on LTCC substrate. Beam is characterized by very low stress, high flatness, and no damage.

Static DC testing is implemented with voltage application through the bias DC pads. Capacitance ratio is measured for shunt switches, and it is obtained using a C-V meter, which allows the capacitance measurement related to the $\mathrm{RF}$ line under the bridge. Optel switches have an up-state capacitance of $0.170 \mathrm{pF}$ and a down-state capacitance of $5.4 \mathrm{pF}$. The capacitance ratio is 31.76 . Contact resistance, for a serie switch, is measured using a multimeter between the suspended bridge and the underpass. Ohmic switches on ceramic substrates have a contact resistance of $6 \Omega$. This high value is due to the ceramic substrate roughness that prevents a well-defined contact area between the suspended membrane and the RF line. A method to obtain a welldefined contact area is under investigation.

Dynamic measures are implemented using a custom setup consisting of a signal generator which drives a high slew rate operational amplifier with high voltage supply, for generation of pulse actuation train (Figure 7).

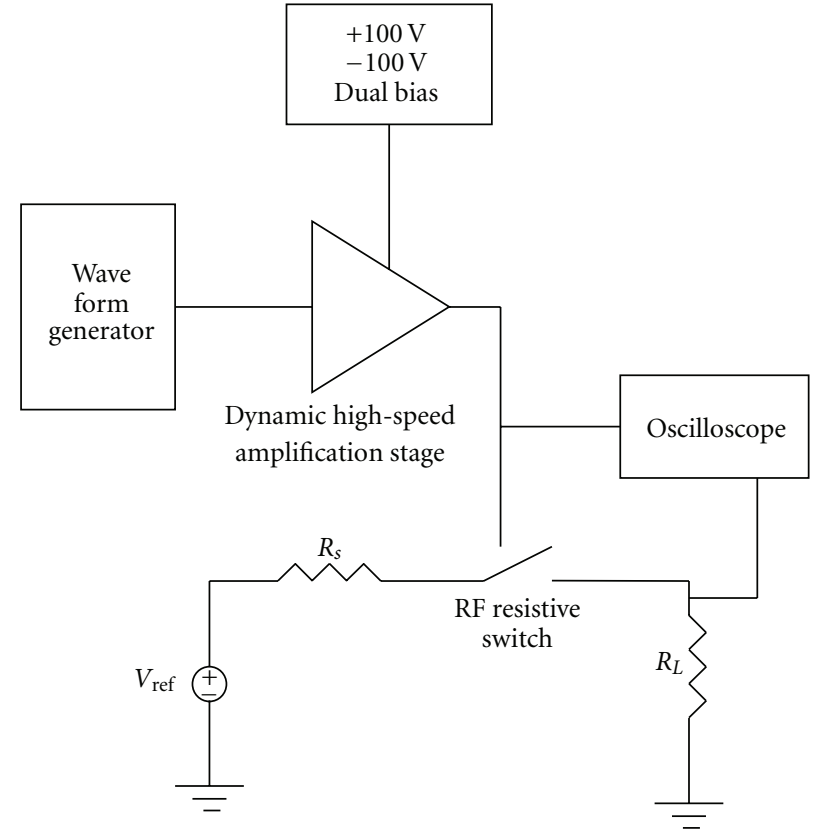

Figure 7: Custom setup of dynamic behaviour measurements for cantilever ohmic switches.

The dynamic measurements are possible with two channels oscilloscope at $10 \mathrm{GS} / \mathrm{s}$ of sample rate, through the serial circuit (Figure 8), with $1 \mathrm{~V}$ voltage supply across the open circuit line [10]. Serie switches show pull-in voltage of $12 \mathrm{~V}$ and actuation and deactuation time of 6 and $14 \mu \mathrm{sec}$. Cantilever topology shows better results than fixed-fixed one.

Electrical endurance lifetime measures are carried out by the same way of dynamic testing, applying a pulse train to obtain $10^{8}$ actuations of the switches. After 100 million actuation cycles, switches show an actuation and deactuation time drift $(30-50 \mu \mathrm{sec})$ and a rising pull-in voltage $(70 \mathrm{~V})$. 


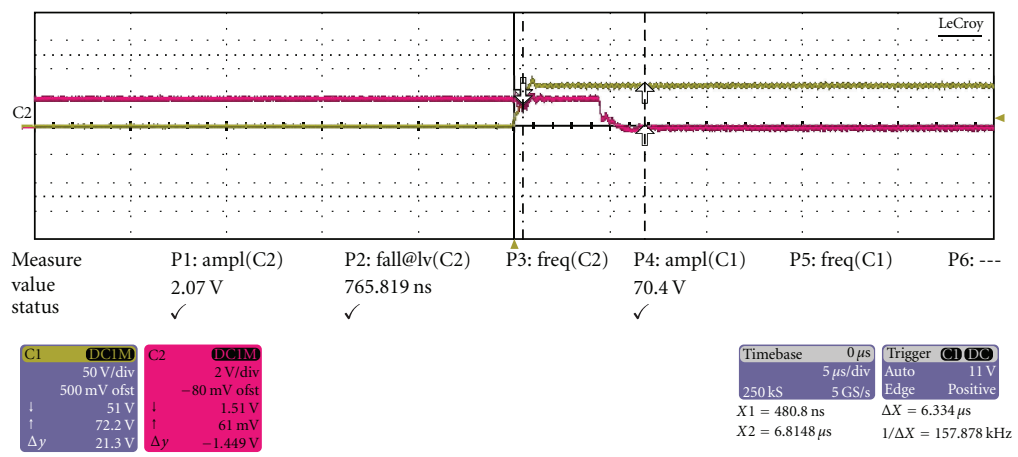

FIGURE 8: Oscilloscope screenshot: measurement of actuation time for cantilever ohmic switch.

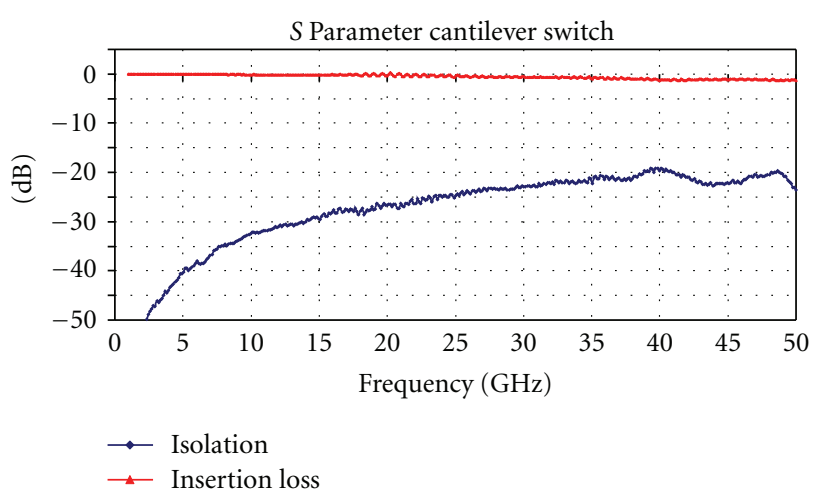

FIGURE 9: Measured insertion loss and isolation of a cantilever switch on alumina substrate.

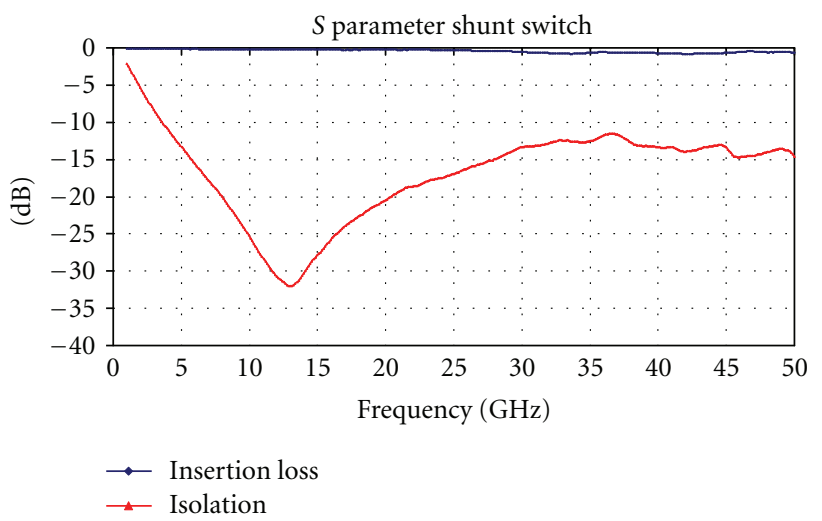

FIGURE 10: Measured insertion loss and isolation of a Shunt switch on alumina substrate.

Anyway, no structural fail has been detected on switches after $10^{8}$ cycles.

$\mathrm{RF}$ testing is implemented using a parametric network Analyzer for measurements of $S$ parameters. In the following graphics, measured return loss, insertion loss and isolation curves are represented. For cantilever switch, isolation is always better than $-20 \mathrm{~dB}$ and insertion loss is about
$-0.4 \mathrm{~dB}$ on the frequency band $1-50 \mathrm{GHz}$ (Figure 9). For shunt switches, measured insertion loss is always better than $-0.25 \mathrm{~dB}$ and isolation is about $-33 \mathrm{~dB}$ at resonance frequency (Figure 10).

Finally, in Table 1, a comparison of performances for three kinds of RF MEMS switches is shown, but presented performances are not closely comparable because they refer to developing research prototypes. Anyway, about Optel switches, cantilever topology has shown the best tradeoff between DC and RF performances. Typically, the main disadvantage of ohmic contact MEMS switches is that they show higher loss with respect to capacitive switches due to the nonzero contact resistance between the bridge and the transmission line, and contact resistance for ceramic substrates is further increased because of an intrinsic roughness of the ceramic. In addition, the contact area is liable to high current density and possible material transfer which can lead to untimely failure, but, on other hand, cantilever switch allows a reduced actuation time and a reduced pull-in voltage with respect to double-anchored switch (fixed-fixed serie and shunt). These aspects have been accurately analyzed and optimized in order to obtain a compact low-loss ohmic contact cantilever MEMS switch.

So, the designed cantilever switch has become a building block of reconfigurable RF MEMS devices. In fact, Optel activity is directed to design devices used in T/R modules for high-frequency communications, such as step delay modules, phase shifters, and power dividers. This kind of devices requires low insertion loss, high reconfigurability, and small size. RF MEMS devices represent an extremely attractive alternative to provide this requirements this is possible because RF MEMS devices guarantee low loss, lowpower consumption, and excellent linearity compared to the traditional MMIC. Also, high-frequency communications require both transmitting and receiving antenna systems with an electronic beam steering, and RF MEMS can be used in a phase shifter to control the phase of the individual radiating element of the antenna array.

\section{Conclusions}

In conclusion, switches have shown a good matching between simulations and measurements. The manufacturing 
technology is very robust, flexible, and low cost, and it provides high reliability, good reproducibility, and complete fulfillment of technical requirements.

Currently, our team is working on future improvements for RF MEMS integration with signal conditioning circuits on ceramics substrates; other developments are RF packaging and interfacing with commercial connectors, a design optimization of switches and complex devices in particular for power handling improvement, ageing, and life time tests in harsh environmental conditions for MIL-std fulfillment, qualification for space applications and satellite communications.

\section{Acknowledgments}

This research activity is partially funded by National Research Program of MIUR no. 800/04 entitled "Enabling Technologies for Microwave Tx/Rx Systems".

\section{References}

[1] J. Bouchaud and H. Wicht, "RF MEMS: status of the industry and roadmaps," in Proceedings of the IEEE Radio Frequency Integrated Circuits (RFIC) Symposium-Digest of Papers, pp. 379-384, June 2005.

[2] G. M. Rebeiz, RF MEMS, Theory, Design and Technology, John Wiely \& Sons, New York, NY, USA, 2002.

[3] S. Chen, T. V. Baughn, Z. J. Yao, and C. L. Goldsmith, "A new in situ residual stress measurement method for a MEMS thin fixed-fixed beam structure," Journal of Microelectromechanical Systems, vol. 11, no. 4, pp. 309-316, 2002.

[4] Y. Pauleau, "Generation and evolution of residual stresses in physical vapour-deposited thin films," Vacuum, vol. 61, no. 24, pp. 175-181, 2001.

[5] Z. Wang, L. Chow, J. L. Volakis, K. Saitou, and K. Kurabuyashi, "Contact physics modeling and optimization design of RFMEMS cantilever switches," in Proceedings of IEEE Antennas and Propagation Society International Symposium and USNC/URSI Meeting, vol. 1A, pp. 81-84, July 2005.

[6] S. C. Saha, T. Singh, and T. Sæther, "Design and simulation of RF MEMS cantilever and bridge switches for high switching speed and low voltage operation and their comparison," in Proceedings of the International Symposium on Signals, Circuits and Systems (ISSCS '05), pp. 131-134, July 2005.

[7] X. Rottenberg, B. Nauwelaers, R. Mertens et al., "RFMEMS metal contact capacitive switches," in Proceedings of the 4th Round Table on Micro/Nano Technologies for Space, Estec, Noordwijk, The Netherlands, May 2003.

[8] G. de Angelis, A. Lucibello, E. Proietti et al., "RF MEMS ohmic switches for matrix configurations," in Proceedings of the 11th International Symposium on RF MEMS and RF Microsystems (MEMSWAVE'10), Otranto, Italy, June 2010.

[9] RADANT MEMS, http://www.radantmems.com/.

[10] C. Calaza, B. Margesin, F. Giacomozzi, K. Rangra, and V. Mulloni, "Electromechanical characterization of low actuation voltage RF MEMS capacitive switches based on DC CV measurements," Microelectronic Engineering, vol. 84, no. 5-8, pp. 1358-1362, 2007. 

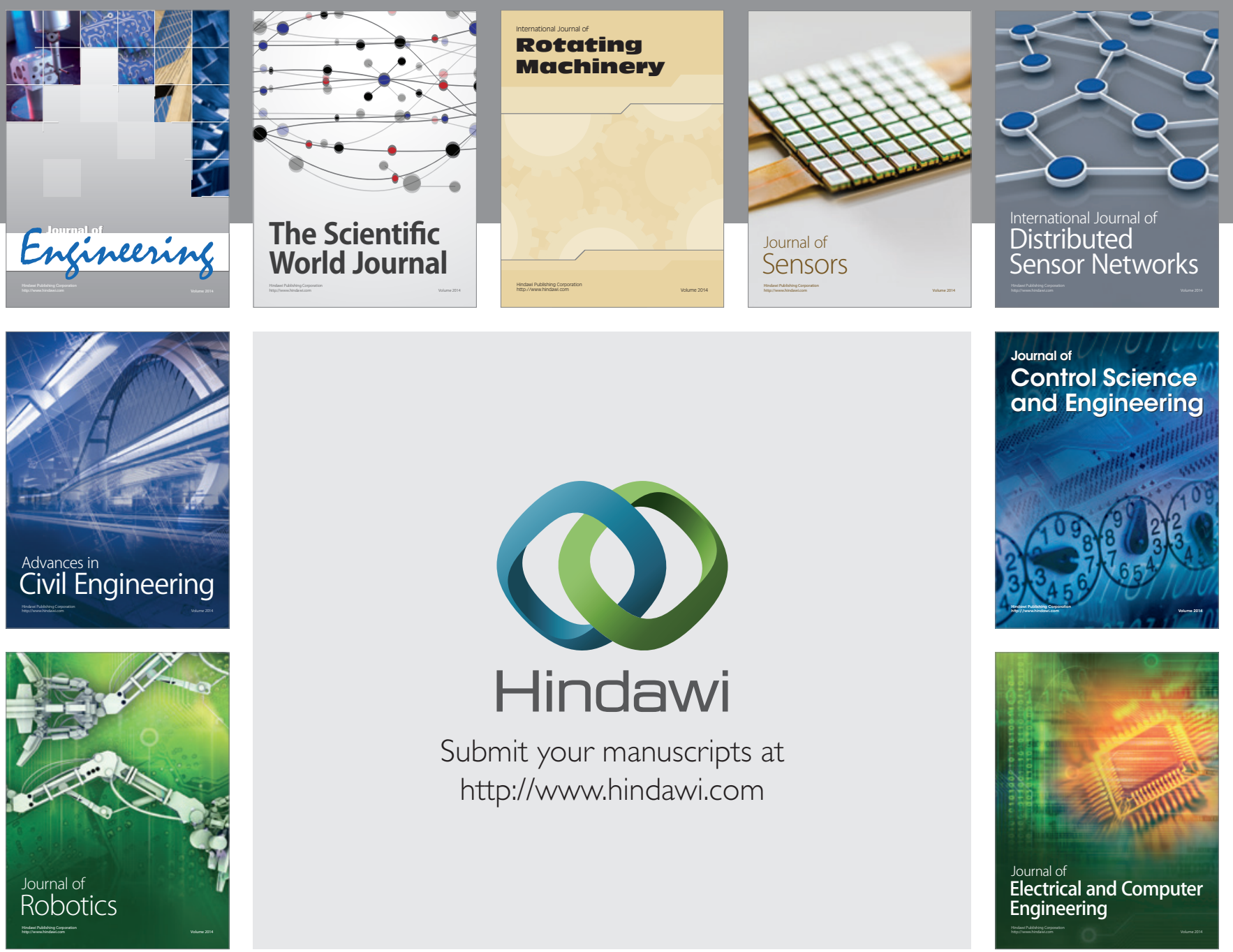

Submit your manuscripts at

http://www.hindawi.com
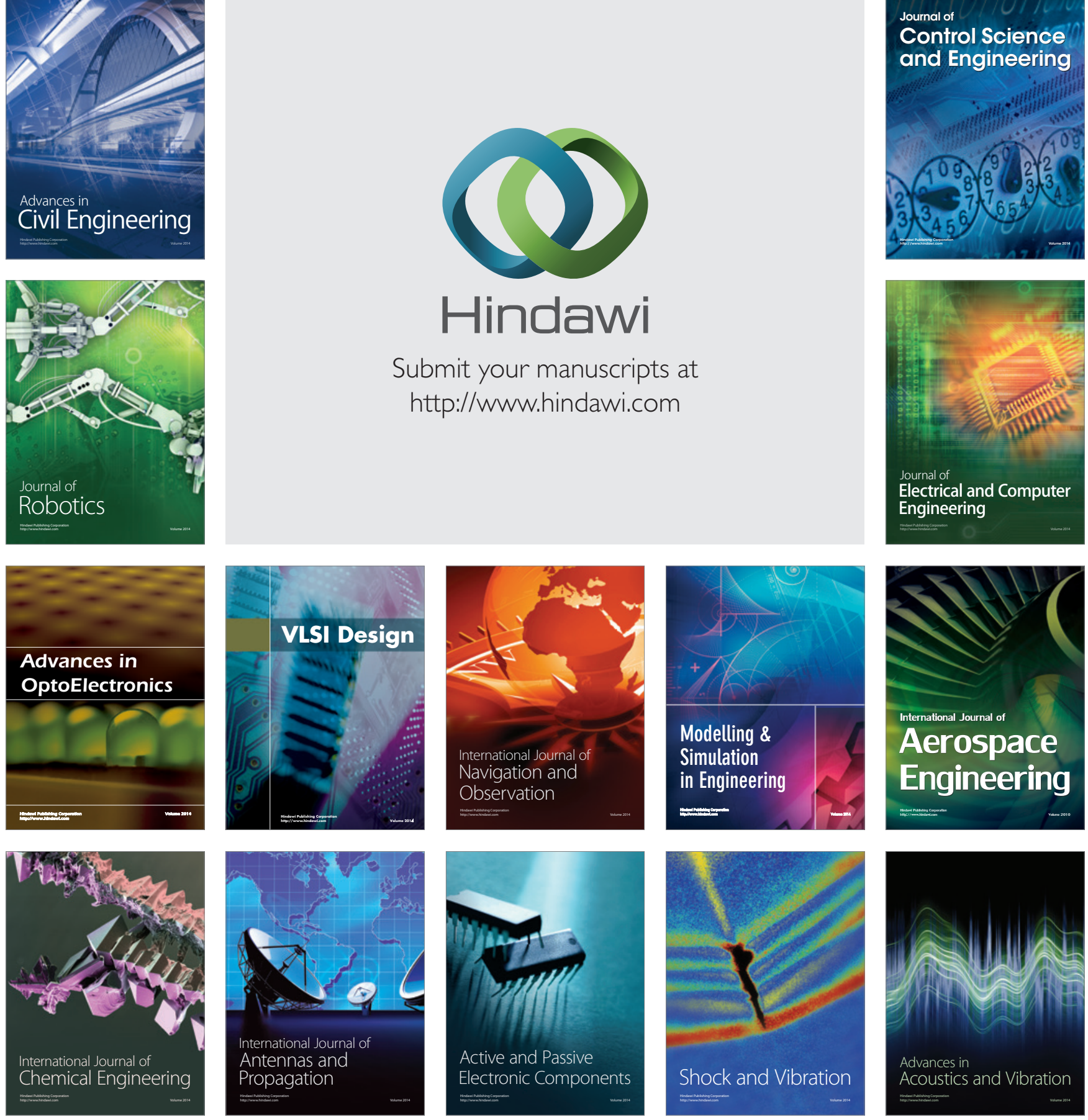